\title{
Brain electrical activity to tones of increasing intensity in fibromyalgia: effects of attentional mechanisms and medication.
}

Noelia Samartin-Veiga ( $\sim$ noelia.samartin.veiga@usc.es)

Universidade de Santiago de Compostela https://orcid.org/0000-0001-9674-6744

Alberto Jacobo González-Villar

"Universidade do Minho"

Yolanda Triñanes

Universidade de Santiago de Compostela

Claudio Gómez-Perretta

Instituto de Investigacion Sanitaria La Fe

María Teresa Carrillo-de-la-Peña

Universidade De Santiago de Compostela

Research article

Keywords: fibromyalgia, auditory evoked potentials (AEP), generalized hypervigilance, central sensory amplification, N1-P2, attentional mechanisms

Posted Date: April 22nd, 2020

DOI: https://doi.org/10.21203/rs.3.rs-23542/v1

License: (c) (1) This work is licensed under a Creative Commons Attribution 4.0 International License. Read Full License 


\section{Abstract \\ Background}

Fibromyalgia (FM) has been associated to an increased central response to noxious somatosensory stimulation, which may be generalized to other sensory modalities. However, the evidence supporting generalized hypervigilance or increased sensory processing is not conclusive. To clarify this, we studied the brain electrical activity associated to auditory stimuli varying in intensity in patients with FM, considering the effects of attentional mechanisms and medication.

\section{Methods}

We performed two experiments using different sequences of stimuli (engaging bottom-up vs. top-down attention). In Study 1, we recorded auditory event-related potentials (AEPs) from 50 patients with FM and 60 healthy controls (HCs), using 72 stimuli of each intensity level $(70,80,90,105 \mathrm{~dB})$ presented randomly within the sequence. In Study 2, the AEPs were recorded from 28 patients with FM and $30 \mathrm{HCs}$ using 3 intensity levels $(70,90,105 \mathrm{~dB})$ of stimuli presented in blocks. For each experiment, we analyzed intensity and group effects on N1-P2 peak-to-peak amplitude using mixed-model ANOVAs and, only for the FM group, the effect of Group of Medication (with vs. without effect on the CNS) and the correlation (Pearson's r) between AEPs and clinical variables.

\section{Results}

In general, the N1-P2 amplitudes were larger at Cz than Fz and, increased as the tone intensity increased. Contrary to the expectation, the patients showed a trend of reduced AEPs to the loudest tones in study 1 and no significant differences with the HCs in study 2. Medication with central effects significantly reduced AEP amplitudes, while no significant relationships between the N1-P2 amplitude/intensity function and patient symptoms were observed.

\section{Conclusions}

Using a large sample, the findings do not provide evidence of augmented central processing of auditory stimuli in FM, nor of its relationship with the symptoms severity. Nevertheless, given the observed effect of medication, we could not discard the role of sensory amplification as an underlying pathophysiological mechanism in fibromyalgia.

\section{Background}

Fibromyalgia (FM) is a complex chronic syndrome that affects around $5 \%$ of the population, producing a remarkable burden on their quality of life [1]. FM is mainly characterized by widespread pain, constant 
tiredness and fatigue, cognitive dysfunction, and non-restorative sleep. Despite extensive research, the etiology and pathogenesis of FM remain unclear. Several studies postulate that the patients with FM present dysfunction of central nervous system mechanisms, affecting both nociceptive and nonnociceptive processing [2-5], and including alteration in the descending pain modulation mechanisms [3, $6]$.

Based on those evidences, it has been proposed that central amplification of painful and non-painful sensory inputs may be at the basis of this syndrome, as well as of other chronic pain diseases [7]. For FM, this hypothesis has received consistent support in the somatosensory modality: patients show increased pain scores and less tolerance to noxious stimuli [8-12] as well as alterations in electroencephalography (EEG) activity and deficits in habituation while processing somatosensory stimuli (painful and non-painful) [13-18]. However, although patients with FM report increased sensitivity to olfactory, auditory and, visual stimuli $[19,20]$, the evidence supporting the generalization of this pattern of central amplification to modalities other than somatosensory is not conclusive.

In the auditory modality, several studies reported augmented subjective perception of tones intensity and lower tolerance to noise by FM patients [19, 21]. Also, using a validated paradigm, -the loudness dependence of the Auditory Evoked Potentials (AEPs)-, Carrillo-de-la-Peña [22] found greater amplitude of the brain electrical response evoked by intense auditory stimuli in FM patients. In contrast, other authors did not find differences in auditory cortical responses between the FM and the control groups [15, 23, 24]. These inconsistencies in the literature may be due to differences in paradigms and stimulation parameters. For instance, some studies employed a paired click paradigm to analyze preattentional components [15; 24], while others analyze later brain responses [22, 23]. In addition, some authors argue that the inconsistent results may be due to the stimuli intensity, sometimes not powerful enough to be unpleasant and to elicit changes in information processing [25]. However, this suggestion goes against the hypothesis of a generalized hypervigilance in FM, which should be present to both nociceptive and harmless stimuli $[26,27]$.

Pain perception and attention proccesses share neural substrates [28, 29]. Different modes of attention to painful stimuli (bottom-up vs. top-down) differentially modulate the evoked brain response [30, 31]. Since the presentation of auditory stimuli in blocks or in a random sequence may engage different attentional procesess [32,33], it would be interesting to analyze the effect of attention on AEPs recorded while processing tones of increasing intensity in a sample of patients with $\mathrm{FM}$, as compared to healthy controls. Also, as previous studies suggest that the effect of medication may explain, at least partially, the inconsistencies in the literature [24,34], the control of this variable is of paramount importante.

Therefore, the aim of the present paper was to analyze the brain electrical activity to auditory stimuli varying in intensity, and whether that response depend on the attentional mechanism involved, in a sample of patients with FM and healthy controls. To this end, we recorded AEPs to two tones sequences: random presentation (study 1 ), where the subject could not anticipate the appearance of the louder stimuli (involving bottom-up mechanisms); and presentation in blocks of equal intensity (study 2), where 
the subject could anticipate the intensity of the following stimuli (involving top-dow mechanims). According to the increased sensory processing hypothesized for FM, we expected to find larger AEPs to the more intense tones in the patients, specially when they are predictable, as in the blocks presentation.

To control for the effect of medication, we compared patients using or not mediation with central effects (antidepressive, anxiolytic, anticonvulsivant, etc). Furthermore, since the intensity dependence of the AEPs has been proposed as an indicator of the serotonin function [35, 36, 37, 38], linked to pain inhibition $[39,40]$ and mood regulation [41], we expected to find a positive correlation between the intensity/amplitude function of the AEPs and FM symptoms severity.

\section{Methods}

\section{Participants:}

For study 1, we recruited 50 patients with FM (mean age: 47.30; SD: 8.00) and 60 healthy controls (HC) (mean age: 45.06; SD: 10.34) and for study 2, 28 patients with FM (mean age: 50.31; SD: 9.20) and $30 \mathrm{HC}$ (mean age: 48.44; SD: 11.18). All the participants were female and both groups were matched for age in each study. The patients with FM had a previous diagnosis confirmed by their primary care physician or rheumatologist and had no other disease that could explain chronic pain nor mental disorders (except mild/moderate levels of depression or anxiety). The same exclusion criteria were applied to the participants of the control group, who also should not have chronic pain problems. Additional exclusion criteria for both groups comprised a history of substance abuse or brain damage.

The diagnosis of participants was confirmed using the 1990 ACR criteria [42] and/or the 2010 ACR criteria $[43,44]$. Moreover, in both studies, the participants were evaluated though a comprehensive clinical interview and several self-reported questionnaires (see Clinical assessment). Also, only in study 1 we assessed the 18 tender points by pressure algometry. Written informed consent was obtained from all the participants and they were coded by numbers. The Ethics Committee of the University of Santiago de Compostela approved the procedure and it was executed in accordance with the Code of Ethics of the Declaration of the World Medical Association in Helsinki, 2013.

\section{Clinical assessment:}

\section{Study 1}

Participants completed several self-reported questionnaires for the assessment of FM symptoms (all in their validated Spanish versions).

Visual-Analogue Scales (VAS): They were created ad-hoc to evaluate the clinical status of participants. The scales consist of a set of horizontal $10 \mathrm{~cm}$-long lines where participants had to indicate their status in the following variables: pain, health status, mood status and, non-restorative sleep. All the scales were presented so that the left end indicated the best condition and, the right the worst. 
Fibromyalgia Impact Questionnaire (FIQ) [45; 46]: The FIQ is a self-reported questionnaire of 10 items to evaluate the health status of patients with FM. It includes indices of functionality as well as the core symptoms of fibromyalgia, with a maximum score of 100 (higher scores are associated to more severe symptoms).

SF-36 Health Survey $[47,48]$ : The SF-36 is a questionnaire that assesses quality of life. It is made up of 36 items that cover 8 dimensions (physical functioning, role physical, bodily pain, general health, vitality, social functioning, role emotional and, mental health) and provide a profile of health status and functionality. For each dimension, the items are coded, added and transformed into a range of 0-100 (from the worst health status to the best health status).

Beck Depression Inventory (BDI) [49; 50]: The BDI evaluates depressive symptomatology using 21 items scored from $0-3$ (the higher the score, the higher the severity of depressive symptoms).

The Pittsburgh Sleep Quality Index (PSQI) [51; 52]: The Spanish validation of the PSQI was used to assess the quality and dysfunction of sleep in the last month. It is composed of 7 subscales (from 0 -no difficulty- to 3 -maximum difficulty-) that describe different aspects of sleep problems. The overall score has an interval of $0-21$, where the highest scores indicate a worse quality of sleep.

Algometry: We measured the pain threshold and tolerance at the 18 tender points using a pressure algometer (Wagner Force One $\rightarrow$, Model FDI; Wagner Instruments, Greenwich, CT, USA). Pressure pain threshold was defined as the minimum force applied that induces pain and, pressure pain tolerance as the maximum pain-pressure value that was bearable. These measures were quantified at each of the 18 specific tender point sites according to the ACR 1990 criteria for FM. A tender point was considered positive when the patient felt pain at pressures equal or less than $4 \mathrm{~kg} / \mathrm{cm}^{2}$. For each participant we calculated the total count of positive tender point and, the mean pain-pressure threshold and tolerance for the 18 points.

\section{Study 2}

As in study 1, the participants completed several self-reported questionnaires (including VAS, BDI and, PSQI). To assess the diagnostic criteria proposed by Wolfe [43], we used the Spanish version of the Fibromyalgia Survey Questionnaire (FSQ) [44] originally published by Wolfe [53]. It includes the Symptom Severity Scale (SSS), which considers 3 key symptoms (fatigue, cognitive problems (attention, concentration or memory) and, non-restorative sleep) and others such as abdominal pain, depression and headache; and the Widespread Pain Index (WPI) that indicates the number of body areas with pain reported by the patient.

\section{Procedure and Task:}

Participants were asked to not smoke, consume coffee, alcohol or other drugs before evaluation. At first, participants completed the clinical interview and self-reported questionnaires. In study 1, the 18 tender points (ACR, 1990) were evaluated in patients and control participants using a pressure algometer. In 
both experiments the participants were seated in a comfortable chair in a room isolated from external sounds and with dim light. After that, participants were fitted with an electrode cap to register their EEG.

In study 1, four patients with FM and one healthy control were discarded due to their high thresholds in the audiometry; also, one patient with FM was eliminated due to an error in the recording. AEPS were obtained using a pseudo-randomized series of 288 auditory stimuli, 72 of each intensity (S1 = 70, S2 = 80, $\mathrm{S} 3=90$ and S4 $=105 \mathrm{~dB}$ SPL). The stimuli had a frequency of $1000 \mathrm{~Hz}$ and a duration of $50 \mathrm{~ms}$, with a random interstimuli interval of $1500 \pm 100 \mathrm{~ms}$. Each intensity was equally preceded by each one of the other 3 intensities.

In study 2, two patients with FM were discarded due to hearing impairment and complains of annoyance by the loudest tones, respectively. The task consisted of 180 trials, 60 of each intensity $(S 1=70, S 2=90$ and S3 $=105 \mathrm{~dB} \mathrm{SPL}$ ), presented in blocks of equal intensity. The stimuli had a frequency of $1000 \mathrm{~Hz}$ and a duration of $50 \mathrm{~ms}$, with a random interstimuli interval of $1400 \pm 100 \mathrm{~ms}$. There were two forms of stimuli presentation (increasing or decreasing intensity) which were counterbalanced across participants.

\section{Recording and processing of AEPs:}

Brain electrical activity was recorded during the presentation of the sounds. In the study 1 , the EEG was recorded using a 32-electrocap (Electro-cap International, Inc., Eaton, OH, USA) and a SynAmps $\rightarrow$ amplifier (Neuroscan Labs, Charlotte, NC, USA) for EEG collection, amplification and online filtering. In the study 2, an ActiChamp system with 32 electrodes cap (Brain Products inc.) was used. The electrodes were placed according to the 10-20 International System, with the reference electrode in the tip of the nose. The ground electrode was placed in the Fpz position. Additional electrodes were placed $1 \mathrm{~cm}$ above and below the eyes and other two were placed on the outer edge of each eye to correct vertical and horizontal eye movements. The EEG was digitized at $500 \mathrm{~Hz}, 10000 \mathrm{x}$ amplified, and filtered with a $0.1-$ $100 \mathrm{~Hz}$ band pass filter and a $50 \mathrm{~Hz}$ notch filter. Impedances were kept below $10 \mathrm{~K} \Omega$.

EEG data were analyzed using the EEGlab 13.3 toolbox [54]. The EEG was re-referenced to an average reference. A spherical-spline interpolation was used to reconstruct bad channels. EEG noisy segments, produced by eye movements or other contaminants, were rejected by visual inspection. The data were digitally filtered using a $0.5 \mathrm{~Hz}$ high pass filter and a $30 \mathrm{~Hz}$ low pass filter. Epochs were extracted from 0.4 seconds pre-stimulus to 1.2 seconds post-stimulus. An extended Independent Component Analysis algorithm (ICA) was applied to the electrophysiological data [55], and components related to ocular or muscular activity were removed after visual inspection.

The EEG epochs used for the analysis of AEPs were corrected using a baseline from -0.2 to 0 seconds. We measured N1 and P2 peak amplitudes at each stimuli intensity in electrodes Fz and Cz, given that these are the locations where such components usually show their greatest amplitudes [32]. In study 1 , the $\mathrm{N} 1$ component was identified as the most negative peak within the range 50-160 ms in $\mathrm{Fz}$, and within the range $90-160 \mathrm{~ms}$ in $\mathrm{Cz}$; and $\mathrm{P} 2$ as the most positive peak within the range $150-250 \mathrm{~ms}$ in Fz and $\mathrm{Cz}$. In study 2, N1 was identified as the most negative peak within the range 80-150 ms in Fz and Cz; 
and $\mathrm{P} 2$ as the most positive peak within the range 150-300 ms in Fz, and within the range 160-300 ms in Cz. The amplitude of N1-P2 was calculated as the peak-to-peak difference.

\section{Data Analyses:}

Student t-tests were performed to evaluate possible differences between groups in demographic and clinical variables. Repeated measures ANOVAs with Electrode (Fz vs. Cz) and Intensity (70, 80, 90, 105 dB or 70,90, $105 \mathrm{~dB}$, for study 1 and 2 respectively) as intra-subject factors and Group (FM vs. HCs) as a between-subject factor were conducted for N1-P2 amplitude in each study. We adjusted the degrees of freedom by the Greenhouse-Geisser correction to determine the significance levels when the sphericity assumption was violated. For patients with FM, we additionally performed a mixed model ANOVA with Electrode and Intensity as intra-subject factors and Medication Group (with vs. without central medication) as a between-subject factor on N1-P2 amplitude. Effect size analyses were undertaken to assess the magnitude of differences between groups. Specifically, Cohen's d was computed for t-tests

and, partial eta-squared $\left[\eta_{p}{ }^{2}\right]$ for ANOVAs. Finally, Pearson's correlation analyses were performed to evaluate the relation between psychophysiological and clinical variables; for this purpose, we first calculated the amplitude/intensity slope of the N1-P2 by linear regression for each subject, as a measure of the intensity dependence of the AEPs. Then, we calculated the correlations with the clinical indices, for the total FM group, and separately for each group of medication. All these statistical analyses were performed with SPSS (v. 20). Significance level was $p$ value $<0.05$

\section{Results}

\section{Study 1}

\section{Demographic and clinical variables}

As may be seen in Table 1, t-tests confirmed that both groups were comparable in age. Patients showed significantly more affectation in all the FM symptoms, as well as lower pressure pain threshold and tolerance values, with large effects sizes effect (Cohen's $d>0.80$ ) [56; pp. 280-287]. Although all the patients were previously diagnosed according to the ACR recommendations [42], we found that 5 of them did not fulfill the criterion of having more than 11 tender points with values lower than $4 \mathrm{~kg} / \mathrm{cm}^{2}$. Due to the criticisms around this criterion [57], we decided to retain those participants for the analyses. 
Table 1

Demographic and clinical variables for patients with fibromyalgia (FM) and healthy controls (HC).

\begin{tabular}{|c|c|c|c|c|c|c|c|}
\hline VARIABLE & $\begin{array}{l}\mathrm{FM} \\
\mathrm{n}\end{array}$ & $\begin{array}{l}\text { FM } \\
\text { Mean(SD) }\end{array}$ & $\begin{array}{l}\mathrm{HC} \\
\mathrm{n}\end{array}$ & $\begin{array}{l}\mathrm{HC} \\
\text { Mean(SD) }\end{array}$ & $t$ & $\mathbf{p}$ & $\begin{array}{l}\text { Cohen's } \\
\text { d }\end{array}$ \\
\hline Age & 50 & $47.30(8.00)$ & 60 & $45.06(10.34)$ & 1.267 & n.s. & - \\
\hline Years of education & 49 & 16.94(4.32) & 56 & $19.11(4.56)$ & -2.49 & $\begin{array}{l}\mathrm{p}< \\
0.05\end{array}$ & 0.20 \\
\hline VAS Pain & 49 & $6.82(1.99)$ & 57 & $1.83(2.14)$ & 12.35 & $\begin{array}{l}p< \\
0.001\end{array}$ & 2.41 \\
\hline VAS Health status & 50 & $6.82(2.20)$ & 57 & $1.87(2.50)$ & 10.79 & $\begin{array}{l}\mathrm{p}< \\
0.001\end{array}$ & 2.10 \\
\hline VAS Mood status & 50 & $4.45(2.81)$ & 57 & $1.69(2.01)$ & 5.77 & $\begin{array}{l}p< \\
0.001\end{array}$ & 1.13 \\
\hline $\begin{array}{l}\text { VAS Non-restorative } \\
\text { sleep }\end{array}$ & 50 & $7.24(2.72)$ & 57 & $2.73(2.92)$ & 8.24 & $\begin{array}{l}p< \\
0.001\end{array}$ & 1.60 \\
\hline FIQ total & 50 & $64.51(15.67)$ & - & - & - & - & - \\
\hline SF36 general & 49 & $41.16(14.16)$ & 57 & 79.80(11.70) & -15.38 & $\begin{array}{l}\mathrm{p}< \\
0.001\end{array}$ & 2.97 \\
\hline BDI & 50 & $19.22(9.43)$ & 58 & $5.57(5.93)$ & 8.84 & $\begin{array}{l}p< \\
0.001\end{array}$ & 1.73 \\
\hline PSQI total & 49 & $12.63(4.44)$ & 56 & $5.21(3.58)$ & 9.467 & $\begin{array}{l}\mathrm{p}< \\
0.001\end{array}$ & 1.84 \\
\hline Tolerance (algometry) & 49 & $3.21(1.04)$ & 58 & $6.11(1.02)$ & -14.49 & $\begin{array}{l}p< \\
0.001\end{array}$ & 2.82 \\
\hline Threshold (algometry) & 49 & $2.42(0.82)$ & 58 & $5.55(0.99)$ & -17.61 & $\begin{array}{l}\mathrm{p}< \\
0.001\end{array}$ & 3.44 \\
\hline $\begin{array}{l}\text { Results of the t-tests co } \\
\text { Fibromyalgia Impact Q } \\
\text { Index; n.s.: non-signific }\end{array}$ & risc & $\begin{array}{l}\text { nd effect si } \\
\text { BDI: Beck L }\end{array}$ & (Co & $\begin{array}{l}\text { 's d). VAS: } \\
\text { Inventory; } F\end{array}$ & $\begin{array}{l}\text { Anal } \\
\text { Pittsb }\end{array}$ & $\begin{array}{l}\text { ue Sc } \\
\text { gh Sle }\end{array}$ & $\begin{array}{l}\text { IQ: } \\
\text { uality }\end{array}$ \\
\hline
\end{tabular}

\section{AEPs to tones}

A repeated measures ANOVA on N1-P2 amplitude showed a significant effect of Electrode $\left[F_{(1,108)}=123.87 ; p<.001 ; \eta_{p}{ }^{2}=0.53\right]$, Intensity $\left[F_{(3,324)}=140.13 ; p<.001 ; \eta_{p}{ }^{2}=0.56\right]$ and, Electrode $x$ Intensity $\left.\left[F_{(3,324}\right)=84.98 ; p<.001 ; \eta_{p}{ }^{2}=0.44\right]$. The amplitudes increased as the stimuli intensity increased, being larger at $\mathrm{Cz}$ than $\mathrm{Fz}$, specially for the highest intensities. Post-hoc comparisons revealed significant differences between each pair of intensity level (S1 vs. S2; S1 vs. S3; S1 vs. S4; S2 vs. S3; S2 vs. S4; S3 vs. S4), in both electrodes. Also we found a significant Intensity $x$ Group interaction $\left[F_{(3,324)}=3.54 ; p=\right.$ $\left.0.039 ; \eta_{p}{ }^{2}=0.03\right]$, with a medium effect size $\left(\eta_{p}{ }^{2}>0.01\right)$. As may be seen in Table 2 , the patients showed 
slightly larger amplitudes to the intensities S1 to S3, but smaller to the S4, as compared to the healthy controls. However, no significant differences were observed in post-hoc comparisons.

Table 2

N1-P2 peak-to-peak amplitudes.

\begin{tabular}{|lllll|}
\hline \multicolumn{3}{|l}{ FM $(\mathbf{n}=\mathbf{4 5})$} & \multicolumn{3}{l|}{ HC $(\mathbf{n = 5 9 )}$} \\
\hline STIMULI & N1-P2 amplitude & \multicolumn{2}{l|}{ N1-P2 amplitude } \\
& Fz & Cz & Fz & Cz \\
\hline S1 (70 dB) & $8.89(3.89)$ & $10.09(4.37)$ & $8.58(3.17)$ & $9.50(3.22)$ \\
\hline S2 (80 dB) & $10.41(4.65)$ & $12.21(4.95)$ & $9.62(3.69)$ & $11.07(3.93)$ \\
\hline S3 (90 dB) & $11.08(4.81)$ & $13.32(5.03)$ & $10.72(4.12)$ & $13.08(4.69)$ \\
\hline S4 (105 dB) & $13.00(5.79)$ & $17.06(7.01)$ & $14.03(5.85)$ & $18.10(7.23)$ \\
\hline
\end{tabular}

N1-P2 peak-to-peak amplitudes (in $\mu \mathrm{V}$ ) measured at the electrodes $\mathrm{Fz}$ and $\mathrm{Cz}$ to the different intensities (S1, S2, S3 and S4) (standard deviations in parentheses), for patients with Fibromyalgia (FM) and healthy controls $(\mathrm{HC})$.

The ANOVA performed to assess the effect of medication in the FM group revealed significant effects for Intensity $\left[F_{(3,48)}=50.78 ; p<.001 ; \eta_{p}{ }^{2}=0.76\right]$, Electrode $\left[F_{(1,23)}=77.52 ; p<.001 ; \eta_{p}{ }^{2}=0.77\right]$, and Intensity $x$ Electrode $\left[F_{(3,144)}=47.89 ; p<.001 ; \eta_{p}^{2}=0.50\right]$. Also, we found a main effect of Group of Medication $\left[F_{(1,48)}=5.15 ; p=.023 ; \eta_{p}{ }^{2}=0.1\right]$, with a medium effect size $\left(\eta_{p}{ }^{2}>0.01\right)$. Post-hoc comparisons revealed that patients using medication with central effects showed smaller N1-P2 amplitudes (mean $=10.70 \mu \mathrm{V}$; $\mathrm{n}=27$ ) than patients without medication affecting the CNS (including non-medicated patients or patients using anti-inflamatory or peripheral analgesics; mean N1-P2 amplitude $=13.55 \mu \mathrm{V} ; n=23$ ), irrespective of the intensity and electrode $\left[F_{(1,48)}=5.15 ; p=.023\right]$. (See Fig. 2).

Finally, we calculated the intensity/amplitude slope of N1-P2 at Cz (because it was the electrode showing the largest amplitudes) for the patients and correlated it with the clinical variables. No significant correlation was observed with any of the FM symptoms (assessed by VAS, FIQ, SF-36, BDI, PSQI, and pain threshold and tolerance values), irrespective of the patients' medication pattern.

\section{Study 2}

\section{Demographic and clinical variables}

As may be seen in Table 3, both groups were comparable in age and level of education. Concerning the clinical variables, patients with FM were overall more affected than controls. Effect size analyses for the clinical variables (VAS, SSS, WPI, BDI and, PSQI) showed a large effect (Cohen's $d>0.80$ ). 
Table 3

Mean values (standard deviations in parentheses) of the demographic and clinical variables.

\begin{tabular}{|c|c|c|c|c|c|c|c|}
\hline VARIABLE & $\begin{array}{l}\mathrm{FM} \\
\mathrm{n}\end{array}$ & $\begin{array}{l}\text { FM } \\
\text { Mean(SD) }\end{array}$ & $\begin{array}{l}\mathrm{HC} \\
\mathrm{n}\end{array}$ & $\begin{array}{l}\mathrm{HC} \\
\text { Mean(SD) }\end{array}$ & $\mathrm{t}$ & $\mathbf{p}$ & $\begin{array}{l}\text { Cohen's } \\
\text { d }\end{array}$ \\
\hline Age & 26 & $50.31(9.20)$ & 27 & $48.44(11.18)$ & 0.66 & n.s. & - \\
\hline Years of education & 26 & $9.96(4.06)$ & 23 & $11.26(4.16)$ & -1.11 & n.s. & - \\
\hline VAS Pain & 28 & $6.24(1.64)$ & 30 & $3.23(3.33)$ & 4.42 & $\begin{array}{l}\mathrm{p}< \\
0.001\end{array}$ & 1.15 \\
\hline VAS Health status & 28 & $6.14(2.09)$ & 30 & $3.65(2.97)$ & 3.70 & $p<0.01$ & 0.97 \\
\hline VAS Mood status & 27 & $5.93(2.40)$ & 30 & $3.75(2.97)$ & 3.03 & $p<0.01$ & 0.81 \\
\hline $\begin{array}{l}\text { VAS Non-restorative } \\
\text { sleep }\end{array}$ & 28 & $6.96(2.28)$ & 30 & $3.61(3.22)$ & 4.60 & $\begin{array}{l}\mathrm{p}< \\
0.001\end{array}$ & 1.20 \\
\hline SSS & 25 & $10.48(1.16)$ & 29 & 7.62(1.95) & 6.64 & $\begin{array}{l}\mathrm{p}< \\
0.001\end{array}$ & 1.78 \\
\hline WPI & 25 & $12.52(4.32)$ & 29 & $1.86(1.98)$ & 11.35 & $\begin{array}{l}\mathrm{p}< \\
0.001\end{array}$ & 3.17 \\
\hline BDI & 27 & 22.93(10.78) & 23 & $10.96(5.60)$ & 6.01 & $\begin{array}{l}\mathrm{p}<0 \\
.001\end{array}$ & 1.39 \\
\hline PSQI total & 27 & $13.48(5.06)$ & 20 & $5.70(3.80)$ & 5.77 & $\begin{array}{l}\mathrm{p}< \\
0.001\end{array}$ & 1.74 \\
\hline \multicolumn{8}{|c|}{$\begin{array}{l}\text { Mean values (standard deviations in parentheses) of the demographic and clinical variables } \\
\text { measured for the patients with fibromyalgia (FM) and healthy controls (HC). Results of the t-tests } \\
\text { comparisons, and effect sizes (Cohen's d). VAS: Visual Analogue Scale; SSS: Symptom Severity } \\
\text { Score; WPI: Widespread Pain Index; BDI: Beck Depression Inventory; PSQI: Pittsburgh Sleep Quality } \\
\text { Index: n.s. non-sianificant. }\end{array}$} \\
\hline
\end{tabular}

\section{AEPs to tones}

As may be seen in Fig. 3, in this study (applying a block presentation) we also observed larger N1-P2 amplitudes over $\mathrm{Cz}$ than $\mathrm{Fz}$ for all the intensities, and similar topographies for $\mathrm{N} 1$ and $\mathrm{P} 2$ than in study 1 . At odds with the previous study, the larger N1-P2 amplitudes were not associated to the loudest tones.

A repeated measures ANOVA on N1-P2 peak-to-peak amplitude showed a significant effect of Electrode $\left[F_{(1,54)}=34.728 ; p=<.001 ; \eta_{p}^{2}=0.39\right]$, Intensity $\left[F_{(2,108)}=20.559 ; p=<.001 ; \eta_{p}{ }^{2}=0.28\right]$ and, Electrode $x$ Intensity $\left[\mathrm{F}_{(2,108)}=18.311 ; \mathrm{p}=<.001 ; \mathrm{n}_{\mathrm{p}}{ }^{2}=0.25\right]$. Post-hoc comparisons revealed that the N1-P2 amplitudes to the highest intensity (S3) were not significantly larger to those for the lowest intensities (S1 or S2). Moreover, the analysis did not show significant main effects nor interactions for Group. 
Table 4

Mean N1-P2 amplitude.

\begin{tabular}{|lllll|}
\hline \multicolumn{3}{|l}{ FM $(\mathbf{n = 2 6 )}$} & \multicolumn{3}{l|}{ HC $(\mathbf{n = 3 0 )}$} \\
\hline STIMULI & N1-P2 amplitude & \multicolumn{2}{l|}{ N1-P2 amplitude } \\
& Fz & Cz & Fz & Cz \\
\hline S1 (70 dB) & $5.41(2.20)$ & $5.92(2.18)$ & $5.96(1.91)$ & $6.45(2.12)$ \\
\hline S2 (90 dB) & $6.39(2.87)$ & $7.62(2.78)$ & $6.75(2.41)$ & $8.40(2.70)$ \\
\hline S3 (105 dB) & $5.37(2.77)$ & $7.48(2.79)$ & $6.08(2.45)$ & $8.66(2.80)$ \\
\hline
\end{tabular}

Mean N1-P2 amplitude (in $\mu \mathrm{V}$ ) in Fz and Cz for each tone intensity (Standard Deviation in parentheses), for the patients with fibromyalgia (FM) and healthy controls (HC).

Regarding medication consumption in patients with FM, the ANOVA showed significant effects for Intensity $\left[F_{(2,46)}=7.74 ; p<.01 ; \eta_{p}{ }^{2}=0.25\right]$, Electrode $\left[F_{(1,23)}=10.34 ; p<.01 ; \eta_{p}{ }^{2}=0.31\right]$ and, Intensity $x$ Electrode $\left[F_{(2,46)}=4.05 ; p=.024 ; \eta_{p}{ }^{2}=0.15\right]$. Although the patients with SNC medication $(n=17)$ showed smaller N1-P2 amplitudes that patients without it $(n=8 ; 5.90 \mu \mathrm{V}$ vs. $7.43 \mu \mathrm{V})$, the effect of Group of medication did not reach the significante level $\left[F_{(1,23)}=3.07 ; p=.093\right]$. (See Fig. 4)

Finally, no significant correlation was found between FM symptoms (assessed by VAS, SSS, WPI, BDI and, PSQI) and the amplitude/intensity slope of the N1-P2 complex in Cz for the patients, regardless of their medication pattern.

\section{Discussion}

It is generally assumed that patients with FM present central alterations in the processing of both nociceptive and non-nociceptive stimuli [58]. The hypotheses of generalized hypervigilance, central sensitization and reduced habituation have been proposed as possible explanatory mechanisms of the FM syndrome $[10,17,18,26]$. However, the evidence is far from being conclusive. Studies analyzing brain activity when processing somatosensory stimulation found evidence in favor of those pathophysiological mechanisms [13-18]. Nevertheless, in the auditory modality the presence of augmented processing is not always observed. To provide clarity in this field, we carried out two studies recording auditory evoked potentials (AEPs) elicited by tones of various intensities in women diagnosed with FM and healthy controls, using different stimuli sequences. The peak-to-peak amplitude of the N1-P2 complex, a reliable index of the amount of neural resources devoted to the processing of auditory stimuli $[35,59]$, was evaluated in both studies. In addition, the effect of medication and the possible relationship between the amplitude/intensity function of the AEPs and the symptomatic picture of the patients were analyzed. Contrary to our hypothesis, we did not find a generalized pattern of sensory amplification in the patients, irrespective of the stimuli sequence used. 
Since bottom-up sensory amplification of nociceptive input may be one cause of the FM symptoms [60], in study 1 we assessed the processing of auditory stimuli when bottom-up mechanisms were engaged. To this end, we used a random presentation of stimuli, where the loudest tones involuntarily capture the participants' attention [32]. Given the hypervigilance -generalized to all kinds of sensory informationassumed for fibromyalgia [26], we expected patients to have higher N1-P2 amplitudes in response to the tones, specially to the most intense ones. Although we found a significant interaction between Group and Intensity (interestingly, with smaller AEPs to the more intense tones in the patients), group differences did not reach significance in the post-hoc comparisons. Therefore, our results do not support the presence of increased processing of auditory stimuli in the patients. In addition, the data do not show evidence of alterations in the automatic assignment of attentional resources to the tones in the patients.

In study 2, we used a presentation in blocks of stimuli of the same intensity to study the effect of anticipatory/preparatory attention on auditory processing. As the most intense tones were predictable, the subjects could anticipate their appearance and put into operation their sensory input inhibitory mechanisms to attenuate their impact. Given that previous studies have found deficits in sensory inhibition in FM, either using somatosensory noxious stimuli [2-6] or annoying high intensity auditory stimulation [19, 22], we expected larger AEPs in the patients, specially in response to the loudest tones. Nevertheless, the findings showed similar brain responses in patients and controls: both groups seem to retain the integrity of their inhibition mechanisms and show a reduction in AEPs amplitude to the $105 \mathrm{~dB}$ tones. Thus, although the patients normally report hypersensitivity to noise [19,20,24], our results from study 2 do not support either the presence of increased processing of auditory stimuli.

This pattern of results is in line with previous studies questioning the generalizability of increased processing and hypervigilance to the auditory modality $[14,15,23,24]$ but disagrees with previous reports of increased AEPs to auditory tones in patients with FM $[19,21,26]$. In particular, our study could not replicate Carrillo-de-la-Peña [22] results, who also used a block presentation and found increased N1-P2 responses to the $105 \mathrm{~dB}$ tones in FM patients. Comparing that paper with the present one, we detect a fundamental difference in relation to the patients' medication: they had a wash-out period of 2 weeks while here patients were not asked to discontinue their medication.

In animal models, it has been proposed that the intensity dependence of AEPs may be an index of serotonergic function [36-38]. That system can be altered by medication with 5-HT effects, which is commonly used by patients with FM. To clarify this issue, we performed additional analyses, using only the FM group. We found that patients with medication affecting the CNS (mainly antidepressants, anxiolytics, analgesics and, anticonvulsants) showed an overall reduction in N1-P2 amplitudes. Similarly, in healthy volunteers previous literature showed a reduced slope of N1-P2 after antidepressant treatment $[34,61-63]$.

On the other hand, taking into account the hypothesized relationship between the intensity dependence of the AEPs and serotonin levels [36-38], and the relationship between serotonin function and pain inhibition [39; 40], we expected to find significant correlations between the N1-P2 amplitude/intensity 
slope and fibromyalgia symptoms severity. However, we obtained no significant results. Similarly, Triñanes [64] found no significant correlations between AEPs amplitude and pressure pain thresholds at the tender points. Since altered serotonin levels have been related to central sensitization and impaired descending inhibitory pathways in FM [65], our results may stem from lack of validity of the intensity/slope index, as previously reported by other authors $[66,67]$.

One of the main limitations of the present study is consumption of medication by patients with FM. Although it would be desirable to have a wash-out period, this measure is not free from criticisms. First, it is questionable to ask patients discontinue treatment when pain and the other symptoms are very severe, what could result in a selection of the mild severity patients. In addition, a wash-out period could produce dependence/tolerance effects, also difficult to control. In any case, the medication effects observed in this report should be taken into account in the design and analyses of future studies. Another possible limitation is that, in order to obtain a more homogeneous sample, we only used women and, therefore our results cannot be generalized to men. Moreover, since the age-of-onset of menopause modulates pain and non-pain sensitivity in women with FM [68], it would be interesting to take into account the early transition to menopause of the participants in future research.

\section{Conclusions}

As a conclusion, using a large sample of participants, we could not replicate previous reports of impaired inhibitory modulation of high intensity tones in patients with FM, independently of the attentional mechanism engaged in the performance of the task. Altough this pattern of findings may challenge the hypothesis of the hypersensitivity/hypervigilance in the auditory modality, given the observed effects of medication, we could not discard it as an etiopathological mechanism for fibromyalgia. Future studies on the brain activity of FM patients should take into account the critical role of pharmacological treatments with central effects. Altogether, these findings are relevant for the search of objective biomarkers and explanatory theories for fibromyalgia using event-related potentials.

\section{List Of Abreviations}

5-HT: seronotine

ACR: American College of Rheumatology

AEPs: Auditory event-related potentials

BDI: Beck Depression Inventory

CNS: Central Nervous System

EEG: Electroencephalography

FIQ: Fibromyalgia Impact Questionnaire 
FM: Fibromyalgia

FSQ: Fibromyalgia Survey Questionnaire

HC: Healthy Controls

ICA: Independent Component Analysis

MED: with CNS medication.

PSQI: Pittsburgh Sleep Quality Index

SSS: Symptom Severity Scale

UNMED: without CNS medication

VAS: Visual Analogue Scales

WPI: Widespread Pain Index

\section{Declarations}

\section{Ethics approval and consent to participate}

The Ethics Committee of the University of Santiago de Compostela approved the procedure of both studies and they were executed in accordance with the Code of Ethics of the Declaration of the World Medical Association in Helsinki, 2013. Also, written informed consent was obtained from all the participants..

\section{Consent for publication}

The informed consent obtained from each participant included a publication consent section that was signed.

\section{Availability of data and materials}

The datasets used and/or analysed during the current study are available from the corresponding author on reasonable request.

\section{Competing interest}

The authors declare that they have no competing interests

\section{Funding}


This study was supported by funding from from the Spanish Government (Ministerio de ciencia e Innovación; ref PSI2009-14555 and, Ministerio de Economía y Competitividad; ref PSI2013-45818-R) and from the Galician Government (Consellería de Cultura, Educación e Ordenación Universitaria; axudas para a consolidación e Estruturación de unidades de investigación competitivas do Sistema universitario de Galicia; grant number GPC 2014/047). A.G.V. was supported by a grant from the Portuguese Foundation for Science and Technology within the scope of the Individual Call to Scientific Employment Stimulus 2017. N.S.V. was supported by a grant from Spanish Government (Ministerio de Economía y Competitividad; grant number BES-2017-082684). The Authors declare that there is no conflict of interest.

\section{Authors' contributions}

All authors contributed substantially to the manuscript. The authors' contributions were as follows: NS-V contributed to EEG recording, data analysis and writing the first draft. AG-V was responsible for the experimental design, EEG recording, data analysis, and manuscript writing and review. YT contributed to experimental design, EEG recording and manuscript review and, CG-P contributed to experimental design and data collection, MTC-P contributed to experimental design, interpretation of the results, manuscript writing and review. Also, all authors have read and approved the paper.

\section{Acknowledgements}

The authors dedicate this article to the memory of our colleague and friend Dr. Claudio Gómez-Perretta. He showed us the way and his light will illuminate us in future steps. We also express our gratitude to all the patients who participated in this study.

\section{References}

[1] Fayaz A, Croft P, Langford RM, Donaldson LJ, Jones GT. Prevalence of chronic pain in the UK: a systematic review and meta-analysis of population studies. BMJ open. 2016;6(6).

[2] Staud R, Craggs JG, Perlstein WM, Robinson ME, Price DD. Brain activity associated with slow temporal summation of $\mathrm{C}$-fiber evoked pain in fibromyalgia patients and healthy controls. European Journal of Pain. 2008;12(8):1078-1089.

[3] Petersel DL, Dror V, Cheung R. Central amplification and fibromyalgia: disorder of pain processing. Journal of neuroscience research. 2011;89(1):29-34.

[4] López-Solà M, Pujol J, Wager, T. D., Garcia-Fontanals, A., Blanco-Hinojo, L., Garcia-Blanco S, ... GarciaFructuoso F. Altered functional magnetic resonance imaging responses to nonpainful sensory stimulation in fibromyalgia patients. Arthritis \& Rheumatology. 2014;66(11):3200-3209.

[5] López-Solà M, Woo CW, Pujol J, Deus J, Harrison, B. J. M, J., Wager TD. Towards a neurophysiological signature for fibromyalgia. . Pain. 2017;158(1):34. 
[6] Jensen KB, Kosek, E., Petzke, F., Carville, S., Fransson, P., Marcus H, ... Gracely R. Evidence of dysfunctional pain inhibition in Fibromyalgia reflected in rACC during provoked pain. Pain. 2009;144(12):95-100.

[7] Suhnan AP, Finch PM, Drummond PD. Hyperacusis in chronic pain: neural interactions between the auditory and nociceptive systems. International journal of audiology. 2017;56(11):801-809.

[8] Bendtsen L, Nørregaard J, Jensen R, Olesen J. Evidence of qualitatively altered nociception in patients with fibromyalgia. . Arthritis \& Rheumatism: Official Journal of the American College of Rheumatology. 1997;40(1):98-102.

[9] Morris V, Cruwys S, Kidd B. Increased capsaicin-induced secondary hyperalgesia as a marker of abnormal sensory activity in patients with fibromyalgia. . Neuroscience letters. 1998;250(3):205-207.

[10] Desmeules JA, Cedraschi, C., Rapiti, E., Baumgartner E, Finckh A, Cohen P, ... Vischer TL. Neurophysiologic evidence for a central sensitization in patients with fibromyalgia. Arthritis \& Rheumatism. 2003;48(5):1420-1429.

[11] Geisser ME, Casey KL, Brucksch CB, Ribbens CM, Appleton BB, Crofford LJ. Perception of noxious and innocuous heat stimulation among healthy women and women with fibromyalgia: association with mood, somatic focus, and catastrophizing. Pain. 2003;102(3):243-250.

[12] Julien N, Goffaux P, Arsenault P, Marchand S. Widespread pain in fibromyalgia is related to a deficit of endogenous pain inhibition. Pain. 2005;114(1-2):295-302.

[13] Gibson SJ, Littlejohn GO, Gorman MM, Helme RD, Granges G. Altered heat pain thresholds and cerebral event-related potentials following painful $\mathrm{CO} 2$ laser stimulation in subjects with fibromyalgia syndrome. Pain. 1994;58(2):185-193.

[14] Lorenz J, Grasedyck K, Bromm B. Middle and long latency somatosensory evoked potentials after painful laser stimulation in patients with fibromyalgia syndrome. Electroencephalography and Clinical Neurophysiology/Evoked Potentials Section. 1996;100(2):165-168.

[15] Montoya P, Sitges C, García-Herrera M, Rodríguez-Cotes A, Izquierdo R, Truyols M, et al. Reduced brain habituation to somatosensory stimulation in patients with fibromyalgia. . Arthritis \& Rheumatism. 2006;54(6):1995-2003.

[16] Diers M, Koeppe C, Diesch E, Stolle AM, HölzI R, Schiltenwolf M, et al. Central processing of acute muscle pain in chronic low back pain patients: an EEG mapping study. Journal of clinical neurophysiology. 2007;24(1):76-83.

[17] de Tommaso M, Federici A, Santostasi R, Calabrese R, Vecchio E, Lapadula G, et al. Laser-evoked potentials habituation in fibromyalgia. The journal of pain. 2011;12(1):116-124. 
[18] de Tommaso M, Nolano M, lannone F, Vecchio E, Ricci K, Lorenzo M, et al. Update on laser-evoked potential findings in fibromyalgia patients in light of clinical and skin biopsy features. Journal of neurology. 2014;261(3):461-472.

[19] Geisser ME, Glass JM, Rajcevska LD, Clauw DJ, Williams DA, Kileny PR, et al. A psychophysical study of auditory and pressure sensitivity in patients with fibromyalgia and healthy controls. The Journal of Pain. 2008;9(5):417-422.

[20] Wilbarger JL, Cook DB. Multisensory hypersensitivity in women with fibromyalgia: implications for well being and intervention. Archives of physical medicine and rehabilitation. 2011;92(4):653-656.

[21] Hollins M, Harper D, Gallagher S, Owings EW, Lim PF, Miller V, et al. Perceived intensity and unpleasantness of cutaneous and auditory stimuli: an evaluation of the generalized hypervigilance hypothesis. Pain. 2009;141(3):215-221.

[22] Carrillo-de-la-Peña MT, Vallet M, Perez MI, Gomez-Perretta C. Intensity dependence of auditory-evoked cortical potentials in fibromyalgia patients: a test of the generalized hypervigilance hypothesis. The Journal of Pain 2006;7(7):480-487.

[23] Lorenz J. Hyperalgesia or hypervigilance? An evoked potential approach to the study of fibromyalgia syndrome. Zeitschrift für Rheumatologie 1998;57(2):S19-S22.

[24] Carrillo-de-la-Peña MT, Triñanes Y, González-Villar A, Gómez-Perretta C, García-Larrea L. Filtering out repetitive auditory stimuli in fibromyalgia: A study of P50 sensory gating. European Journal of Pain. 2015;19(4):576-584.

[25] Peters ML, Vlaeyen JW, van Drunen C. Do fibromyalgia patients display hypervigilance for innocuous somatosensory stimuli? Application of a body scanning reaction time paradigm. Pain. 2000;86(3):283292.

[26] McDermid AJ, Rollman GB, McCain GA. Generalized hypervigilance in fibromyalgia: evidence of perceptual amplification. Pain. 1996;66(2-3):133-144.

[27] Hollins M, Walters S. Experimental hypervigilance changes the intensity/unpleasantness ratio of pressure sensations: evidence for the generalized hypervigilance hypothesis. Experimental brain research. 2016;234(6):1377-1384.

[28] Schmidt-Wilcke T, Kairys A, Ichesco E, Fernandez-Sanchez ML, Barjola P, Heitzeg M, et al. Changes in clinical pain in fibromyalgia patients correlate with changes in brain activation in the cingulate cortex in a response inhibition task. Pain medicine. 2014;15(8):1346-1358.

[29] Torta DM, Legrain V, Mouraux A, Valentini E. Attention to pain! A neurocognitive perspective on attentional modulation of pain in neuroimaging studies. Cortex. 2017;89:120-134. 
[30] Hauck M, Lorenz J, Domnick C, Gerloff C, Engel AK. Top-down and bottom-up modulation of paininduced oscillations. Frontiers in human neuroscience. 2015;9:375.

[31] Tiemann L, May ES, Postorino M, Schulz E, Nickel MM, Bingel U, et al. Differential neurophysiological correlates of bottom-up and top-down modulations of pain. Pain. 2015;156(2):289-296.

[32] Carrillo-de-la-Peña MT. Effects of intensity and order of stimuli presentation on AEPs: an analysis of the consistency of EP augmenting/reducing in the auditory modality. Clinical neurophysiology. 1999;110(5):924-932.

[33] Carrillo-de-la-Peña MT. One-year test-retest reliability of auditory evoked potentials (AEPs) to tones of increasing intensity. Psychophysiology 2001;38(3):417-424.

[34] Nathan PJ, Segrave R, Phan KL, O'Neill B, Croft RJ. Direct evidence that acutely enhancing serotonin with the selective serotonin reuptake inhibitor citalopram modulates the loudness dependence of the auditory evoked potential (LDAEP) marker of central serotonin function. Human Psychopharmacology: Clinical and Experimental. 2006;21(1):47-52.

[35] Hegerl U, Juckel G. Intensity dependence of auditory evoked potentials as an indicator of central serotonergic neurotransmission: a new hypothesis. Biological psychiatry. 1993;33(3):173-187.

[36] Juckel G, Molnár M, Hegerl U, Csépe V, Karmos G. Auditory-evoked potentials as indicator of brain serotonergic activity first evidence in behaving cats. Biological psychiatry. 1997;41(12):1181-1195.

[37] Juckel G, Hegerl U, Molnár M, Csépe V, Karmos G. Auditory evoked potentials reflect serotonergic neuronal activity-a study in behaving cats administered drugs acting on 5-HT $1 \mathrm{~A}$ autoreceptors in the dorsal raphe nucleus. Neuropsychopharmacology. 1999;21(6):710-716.

[38] Wutzler A, Winter C, Kitzrow W, Uhl I, Wolf RJ, Heinz A, et al. Loudness dependence of auditory evoked potentials as indicator of central serotonergic neurotransmission: simultaneous electrophysiological recordings and in vivo microdialysis in the rat primary auditory cortex. Neuropsychopharmacology. 2008;33(13):3176-3181.

[39] Bardin L. The complex role of serotonin and 5-HT receptors in chronic pain. Behavioural pharmacology. 2011;22(5-6):390-404.

[40] Martin SL, Power A, Boyle Y, Anderson IM, Silverdale MA, Jones AK. 5-HT modulation of pain perception in humans. Psychopharmacology, 2017;234(19):2929-2939.

[41] Paul-Savoie E, Potvin S, Daigle K, Normand E, Corbin JF, Gagnon R, et al. A deficit in peripheral serotonin levels in major depressive disorder but not in chronic widespread pain. The Clinical journal of pain. 2011;27(6):529-534. 
[42] Wolfe F, Smythe HA, Yunus MB, Bennett RM, Bombardier C, Goldenberg DL, et al. The American College of Rheumatology 1990 criteria for the classification of fibromyalgia. . Arthritis \& Rheumatism: Official Journal of the American College of Rheumatology. 1990;33(2):160-172.

[43] Wolfe F, Clauw DJ, Fitzcharles MA, Goldenberg DL, Katz RS, Mease P, et al. The American College of Rheumatology preliminary diagnostic criteria for fibromyalgia and measurement of symptom severity. Arthritis care \& research. 2010;62(5):600-610.

[44] Carrillo-de-la-Peña MT, Triñanes Y, González-Villar A, Romero-Yuste S, Gómez-Perretta C, Arias M, et al. Convergence between the 1990 and 2010 ACR diagnostic criteria and validation of the Spanish version of the Fibromyalgia Survey Questionnaire (FSQ). . Rheumatology international 2015;35(1):141151.

[47] Ware Jr JE, Sherbourne CD. The MOS 36-item short-form health survey (SF-36): I. Conceptual framework and item selection. Medical care. 1992:473-483.

[48] Alonso J, Prieto L, Anto JM. The Spanish version of the SF-36 Health Survey (the SF-36 health questionnaire): an instrument for measuring clinical results. Medicina clínica. 1995;104(20):771-776.

[45] Burckhardt CS, Clark SR, Bennett RM. The fibromyalgia impact questionnaire: development and validation. The Journal of rheumatology. 1991;18(5):728-733.

[46] Monterde S, Salvat I, Montull S, Fernández-Ballart J. Validación de la versión española del Fibromyalgia Impact Questionnaire. Revista Española de Reumatología. 2004;31(9):507-13.

[49] Beck AT, Steer RA, Carbin MG. Psychometric properties of the Beck Depression Inventory: Twenty-five years of evaluation. Clinical psychology review. 1988;8(1):77-100.

[50] Sanz J, Vázquez C. Fiabilidad, validez y datos normativos del inventario para la depresión de Beck. . Psicothema. 1998;10(2):303-318.

[51] Buysse DJ, Reynolds CF, Monk TH, Berman SR, Kupfer DJ. The Pittsburgh Sleep Quality Index: a new instrument for psychiatric practice and research. Psychiatry research. 1989;28(2):193-213.

[52] Macías JA, Royuela A. The Spanish version of the Pittsburgh Sleep Quality Index. . Infor Psiquiatr. 1996;146(465):472.

[53] Wolfe F, Clauw DJ, Fitzcharles MA, Goldenberg DL, Häuser W, Katz RS, et al. Fibromyalgia criteria and severity scales for clinical and epidemiological studies: a modification of the ACR Preliminary Diagnostic Criteria for Fibromyalgia. The Journal of rheumatology. 2011;38(6):1113-1122.

[54] Delorme A, Makeig S. EEGLAB: an open source toolbox for analysis of single-trial EEG dynamics including independent component analysis. Journal of neuroscience methods. 2004;134(1):9-21. 
[55] Makeig S, Bell AJ, Jung TP, Sejnowski TJ. Independent component analysis of electroencephalographic data. In Advances in neural information processing systems. 1996:145-151.

[56] Cohen J. Statistical power analysis for the behavioral sciences. Abingdon England: Routledge; 1998.

[57] Wolfe F. The relation between tender points and fibromyalgia symptom variables: evidence that fibromyalgia is not a discrete disorder in the clinic. . Annals of the rheumatic diseases. 1997;56(4):268271.

[58] Sluka KA, Clauw DJ. Neurobiology of fibromyalgia and chronic widespread pain. Neuroscience. 2016;338(114):129.

[59] Hansen JC, Hillyard SA. Endogeneous brain potentials associated with selective auditory attention. Electroencephalography and clinical neurophysiology. 1980;49(3-4):277-290.

[60] Guymer EK, LittleJohn GO. Fibromyalgia: top down or bottom up? . APLAR Journal of Rheumatology. 2007;10(3):174-177.

[61] Kähkönen S, Jääskeläinen IP, Pennanen S, Liesivuori J, Ahveninen J. Acute trytophan depletion decreases intensity dependence of auditory evoked magnetic N1/P2 dipole source activity. Psychopharmacology. 2002;164(2):221-227.

[62] Segrave R, Croft RJ, Illic S, Phan KL, Nathan PJ. Pindolol does not augment central serotonin function increases to citalopram in humans: an auditory evoked potential investigation. Pharmacology Biochemistry and Behavior. 2006;85(1):82-90.

[63] Simmons JG, Nathan PJ, Berger G, Allen NB. Chronic modulation of serotonergic neurotransmission with sertraline attenuates the loudness dependence of the auditory evoked potential in healthy participants. . Psychopharmacology. 2011;2017(1):101-110.

[64] Triñanes Y, González-Villar A, Gómez-Perretta C, Carrillo-de-la-Peña MT. Profiles in fibromyalgia: algometry, auditory evoked potentials and clinical characterization of different subtypes. . Rheumatology international. 2014;34(11):1571-1580.

[65] Bou Khalil R, Khoury E, Richa S. Do fibromyalgia flares have a neurobiological substrate? Pain Medicine. 2016;17(3):469-475.

[66] Dierks T, Barta S, Demisch L, Schmeck K, Englert E, Kewitz A, et al. Intensity dependence of auditory evoked potentials (AEPs) as biological marker for cerebral serotonin levels: effects of tryptophan depletion in healthy subjects. . Psychopharmacology. 1999;146(1):101-107.

[67] Beauducel A, Debener S, Brocke B, Kayser J. On the reliability of augmenting/reducing: Peak amplitudes and principal component analysis of auditory evoked potentials. . Journal of Psychophysiology. 2000;14(4):226-240. 
[68] Martínez-Jauand M, Sitges C, Femenia J, Cifre I, González S, Chialvo D, et al. Age-of-onset of menopause is associated with enhanced painful and non-painful sensitivity in fibromyalgia. Clinical rheumatology. 2013;32(7):975-981.

\section{Figures}
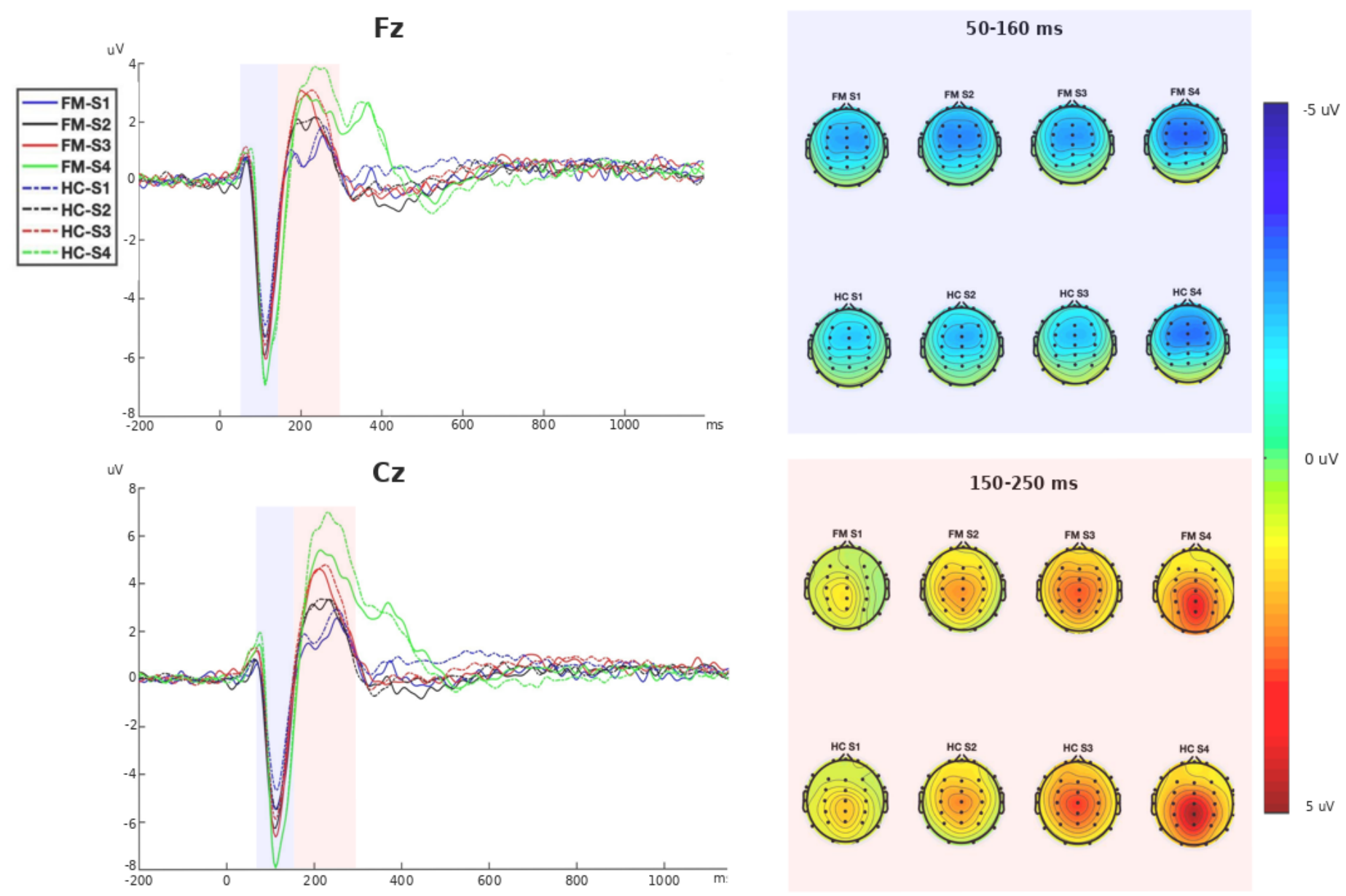

\section{Figure 1}

Right. Electrical brain activity in response to auditory stimulation in patients with fibromyalgia (FM) and healthy controls $(\mathrm{HC})$. The waveforms represent the auditory evoked potentials (AEPs) at electrodes Fz (up) and $\mathrm{Cz}$ (bottom) elicited by the tones of $70 \mathrm{~dB}$ (S1; blue line), $80 \mathrm{~dB}$ (S2; black line), $90 \mathrm{~dB}$ (S3; red line) and, $105 \mathrm{~dB}$ (S4; green line). Left. Spatial distribution of the electrical activity elicited by stimuli of different intensities. The upper part shows the topographic representation of $\mathrm{N} 1$ (measured as the mean value from 50-160 ms after the presentation of the stimuli), and the lower part shows the topography of P2 (measured from 150-250 ms). 
Fz
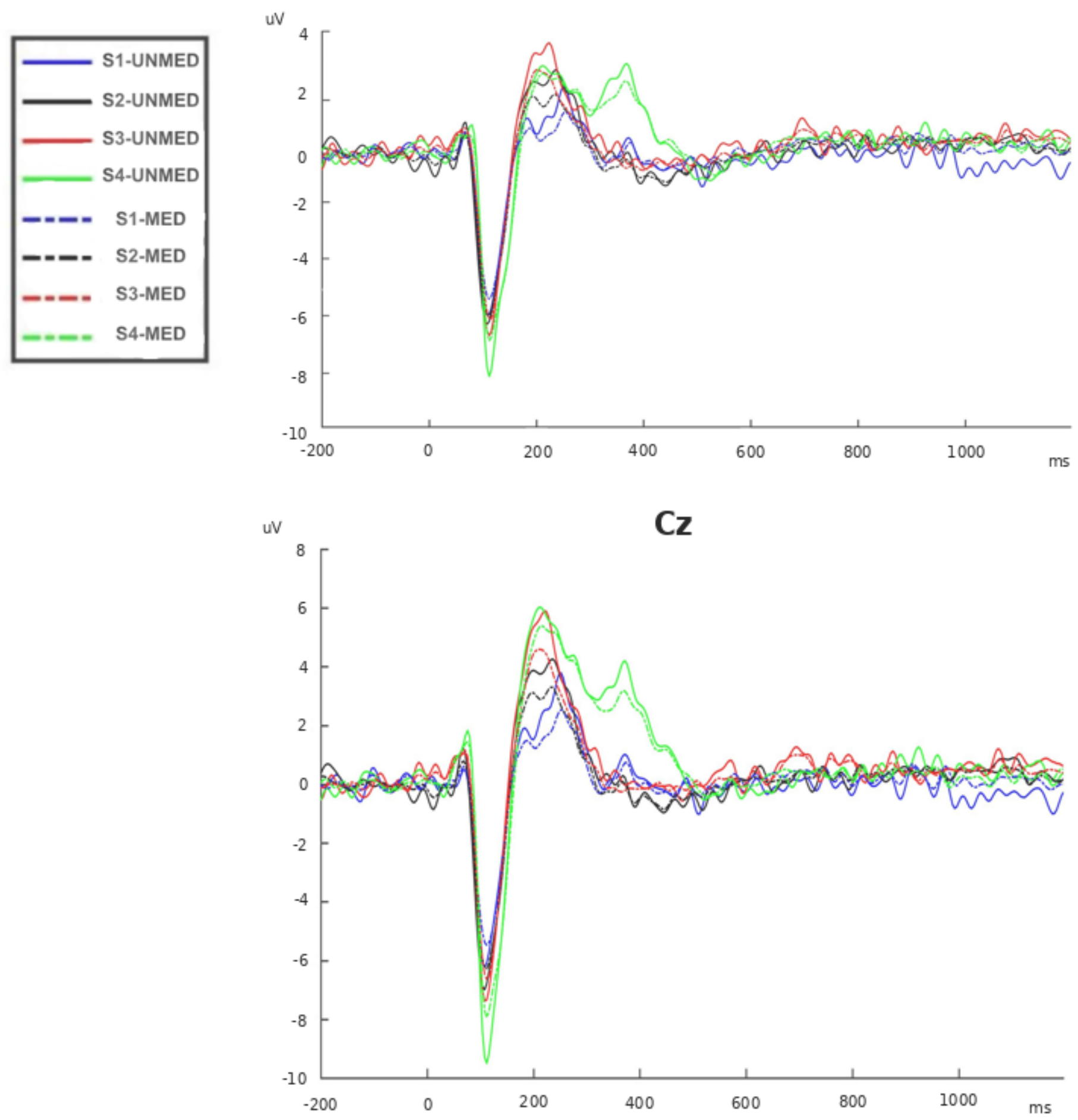

Figure 3

Electrical brain activity in response to auditory stimulation in patients with fibromyalgia without CNS medication (UNMED) or with CNS medication (MED). The waveforms represent the auditory evoked potentials (AEPs) at electrodes $\mathrm{Fz}$ (up) and $\mathrm{Cz}$ (bottom) elicited by the tones of $70 \mathrm{~dB}$ ( $\mathrm{S} 1$; blue line), 80 $\mathrm{dB}$ (S2; black line), $90 \mathrm{~dB}$ (S3; red line) and, $105 \mathrm{~dB}$ (S4; green line). 


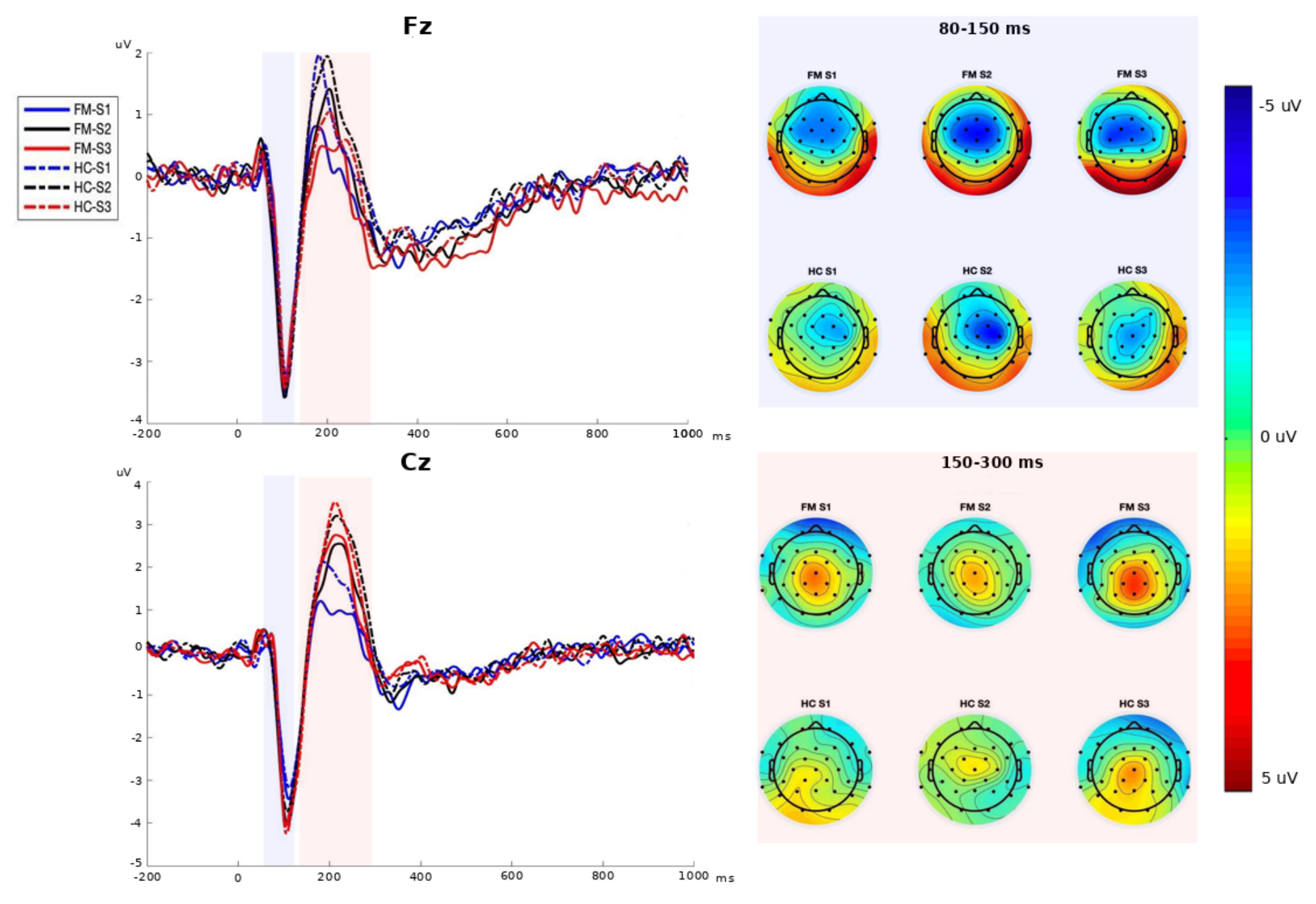

\section{Figure 6}

Right. Auditory evoked potentials (AEPs) at electrodes Fz and Cz elicited by the tones of $70 \mathrm{~dB}$ (S1; blue line), $90 \mathrm{~dB}$ (S2; black line) and, $105 \mathrm{~dB}$ (S3; red line) in patients with fibromyalgia (FM) and healthy controls (HC). Left. Scalp distribution of AEP amplitudes elicited by the three stimuli. The upper part shows the topography of $\mathrm{N} 1$ (measured as the mean value from 80-150 ms), and the lower part shows the topography of P2 (measured from 150-300 ms). 

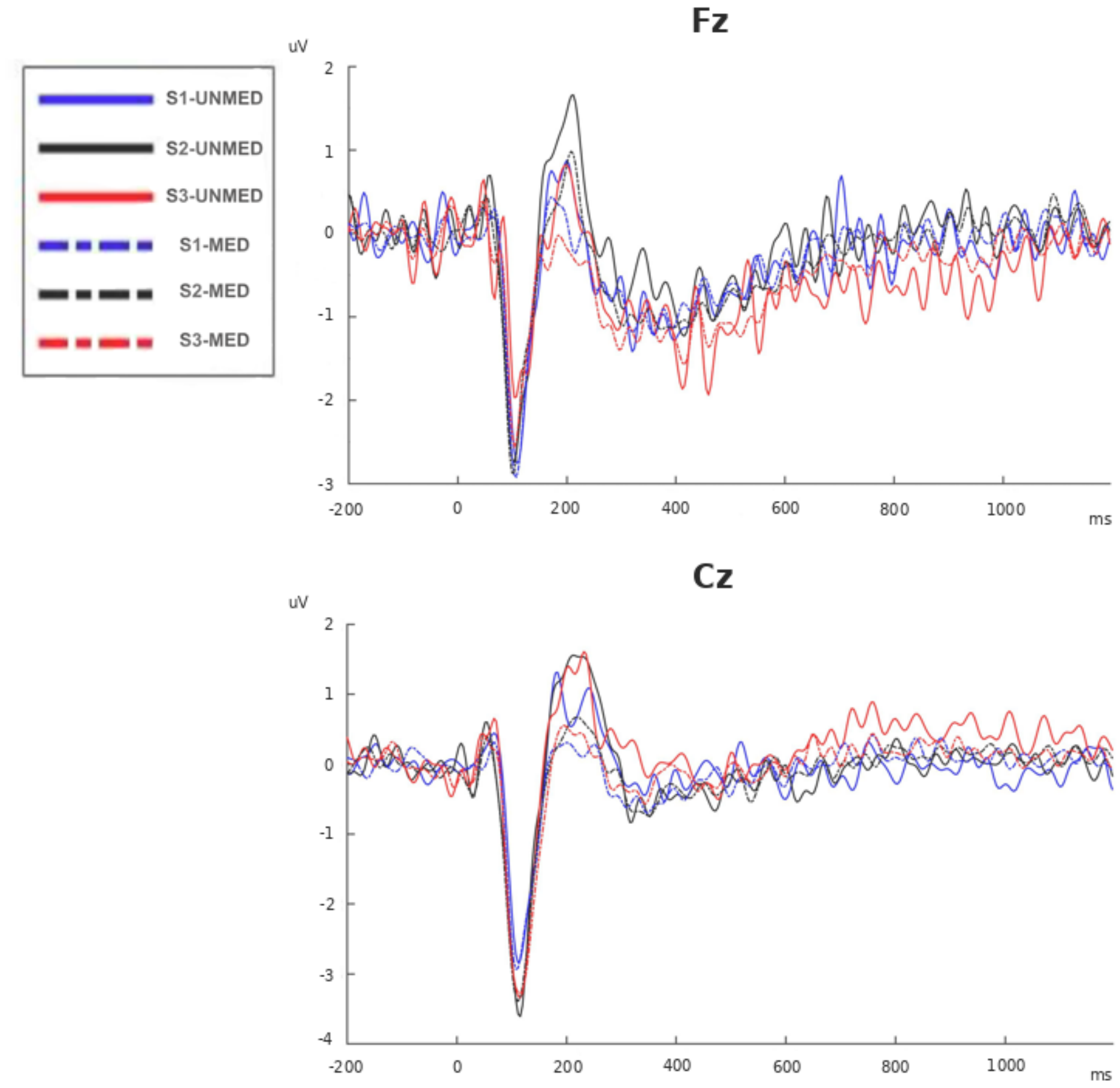

Figure 8

Auditory evoked potentials (AEPs) at electrodes Fz (up) and Cz (down) elicited by the tones of $70 \mathrm{~dB}$ (S1; blue line), $90 \mathrm{~dB}$ (S2; black line) and, $105 \mathrm{~dB}$ (S3; red line) in patients with FM (without medication (UNMED), and with medication of the CNS (MED)). 